\title{
Porphyrin nanochannels reinforced by hydrogen bonding†‡:
}

\author{
Tomoya Ishizuka, ${ }^{a}$ Muniappan Sankar, ${ }^{a}$ Yusuke Yamada, ${ }^{b}$ Shunichi Fukuzumi ${ }^{b, c}$ and Takahiko Kojima ${ }^{* a}$
}

Received (in $X X X, X X X) X$ th $X X X X X X X X X 20 X X$, Accepted Xth $X X X X X X X X X 20 X X$

DOI: $10.1039 / b 000000 x$

${ }_{5}$ Carboxyl groups were introduced at the peripheral positions of dodecaphenylporphyrin to link nanochannel structures with intermolecular hydrogen bonds to make the supramolecular structures robust.

Hydrogen bonding ${ }^{1}$ plays indispensable roles in nature to 10 determine the physical properties of protic solvents such as water, ${ }^{2}$ to construct and regulate the high-dimensional structures of proteins and $\mathrm{DNA}^{3}$, and to make it possible for optical functional molecules to exhibit the functionality by tuning the molecular flexibility, which highly affects the lifetimes of excited 15 states of molecules. ${ }^{4}$ In recent years, supramolecular structures formed by hydrogen bonding have attracted considerable attention due to the interest in molecular sensors ${ }^{5}$, protonconductivity, ${ }^{6}$ and future application to manufacturing integrated circuits. ${ }^{7}$ Hydrogen bonding is also highly promising to construct 20 molecular networks holding a porous structure applicable for gas storage, gas separation and catalytic activities, ${ }^{8}$ due to its high directionality.

We have reported the formation of porphyrin nanochannel structures $^{9}$ with a saddle-distorted porphyrin derivative, ${ }_{25}$ dodecaphenylporphyrin $\left(\mathrm{H}_{2} \mathrm{DPP}, \mathbf{1}\right){ }^{10,11}$ where the porphyrin $\mathbf{1}$ was diprotonated and the intermolecular $\pi-\pi$ interaction between the peripheral phenyl groups played a main role to assemble the porphyrins into the supramolecular structure. ${ }^{12}$ The inner spaces of the nanochannels formed can be used for inclusion of electron30 donating guest molecules to exhibit photovoltaic cell properties. $^{9(\mathrm{c})}$ The nanochannel structure, however, was very fragile upon loss of the solvent molecules of crystallization, and thus, the range of applications for the nanochannels is limited. In this study, we have introduced multi-hydrogen-bonding sites to

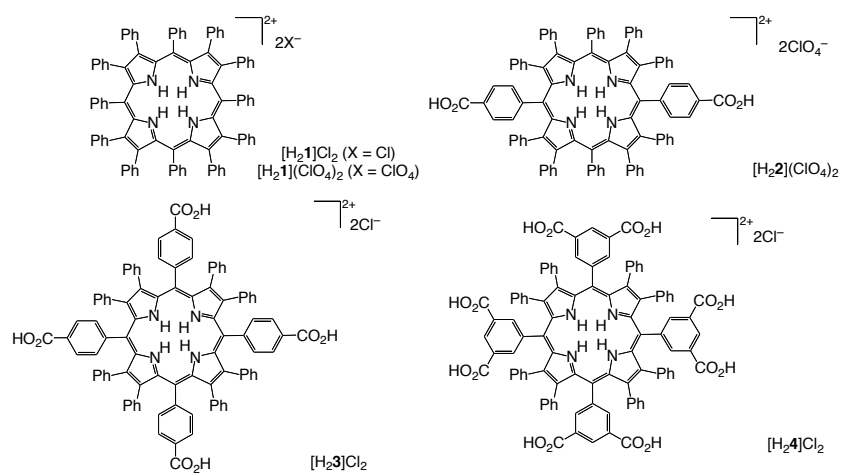

Fig. 1 Schematic description of structures of diprotonated salts of carboxyl-substituted porphyrins $\mathbf{1}-\mathbf{4}$.

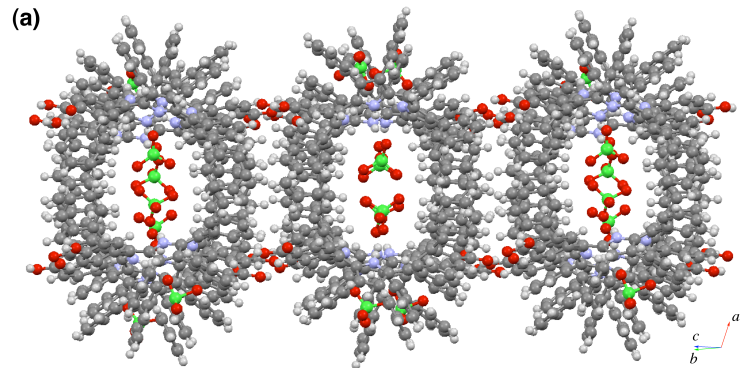

(b)

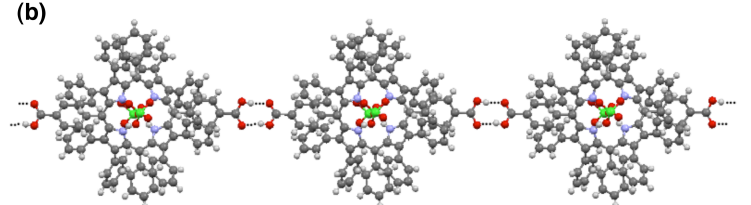

Fig. 2 Crystal structures of $\left[\mathrm{H}_{2} 2\right]\left(\mathrm{ClO}_{4}\right)_{2}$. (a) Nanochannel and (b) 1-D Hydrogen-bonding wire.

the DPP structure ${ }^{13}$ to form a robust porous structure bearing 40 unique optical properties and high chemical reactivities.

Herein, we have employed four kinds of saddle-distorted porphyrins 1-4 (Fig. 1), each of which has different numbers $(n)$ of carboxyl groups on the meso-aryl groups: $n=0(\mathbf{1}), n=2(\mathbf{2}), n$ $=4(3)$, and $n=8$ (4). The porphyrin 1 and the dichloride salt ${ }_{45}\left(\left[\mathrm{H}_{2} \mathbf{1}\right] \mathrm{Cl}_{2}\right)$ were synthesized by a reported procedure, ${ }^{9}$ and the perchlorate salt $\left(\left[\mathrm{H}_{2} \mathbf{1}\right]\left(\mathrm{ClO}_{4}\right)_{2}\right)$ was prepared with treatment of the solution of 1 in $\mathrm{CHCl}_{3}$ with perchloric acid. The carboxylporphyrins 2-4 were synthesized from the corresponding alkoxyester-substituted tetraphenylporphyrins through sequential ${ }_{50}$ reactions (see ESI). Porphyrin 2 has two carboxyl groups at the para-positions of the two meso-phenyl groups at the 5- and 15positions, and the para-positions of all the four meso-phenyl groups of $\mathbf{3}$ are substituted by carboxyl groups. Porphyrin $\mathbf{4}$ bears four 3,5-dicarboxy-phenyl groups at the meso-positions. Thus, ${ }_{55}$ porhyrins $\mathbf{2}, \mathbf{3}$, and $\mathbf{4}$ possess two, four, and eight carboxyl groups in total, respectively, in the structures. Porphyrin $\mathbf{2}$ was diprotonated with perchloric acid to give the perchlorate salt, $\left[\mathrm{H}_{2} 2\right]\left(\mathrm{ClO}_{4}\right)_{2}{ }^{13}$ Dichloride salts of $\mathbf{3}$ and $\mathbf{4}\left(\left[\mathrm{H}_{2} 3\right] \mathrm{Cl}_{2}\right.$ and $\left[\mathrm{H}_{2} 4\right] \mathrm{Cl}_{2}$ ) were obtained by treatment with hydrochloric acid.

${ }_{60}$ The diprotonated salts obtained were recrystallized with vapordiffusion method from $\mathrm{CHCl}_{3} / \mathrm{CH}_{3} \mathrm{CN}$ for $\left[\mathrm{H}_{2} \mathbf{1}\right] \mathrm{Cl}_{2},{ }^{9 \mathrm{~b}} \mathrm{THF} / \mathrm{EtOH}$ for $\left[\mathrm{H}_{2} \mathbf{1}\right]\left(\mathrm{ClO}_{4}\right)_{2}$, THF/EtOH for $\left[\mathrm{H}_{2} 2\right]\left(\mathrm{ClO}_{4}\right)_{2}, \mathrm{THF} / \mathrm{MeOH}$ for $\left[\mathrm{H}_{2} 3\right] \mathrm{Cl}_{2}, \mathrm{THF} / \mathrm{EtOH} /$ cyclohexane for $\left[\mathrm{H}_{2} 4\right] \mathrm{Cl}_{2}$, and each structure was determined by single-crystal X-ray diffraction 65 analysis.

$\left[\mathrm{H}_{2} \mathbf{1}\right]\left(\mathrm{ClO}_{4}\right)_{2}$ included two perchlorate ions above and below 
(a)

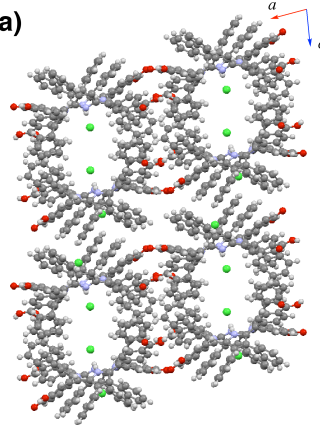

(b)

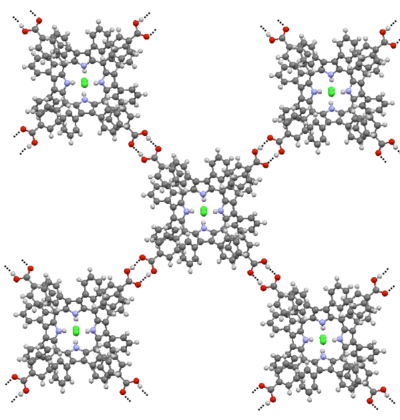

Fig. 3 Crystal structures of $\left[\mathrm{H}_{2} 3\right] \mathrm{Cl}_{2}$. (a) Nanochannel along the $b$-axis and (b) 2-D Hydrogen-bonding sheet.

(a)

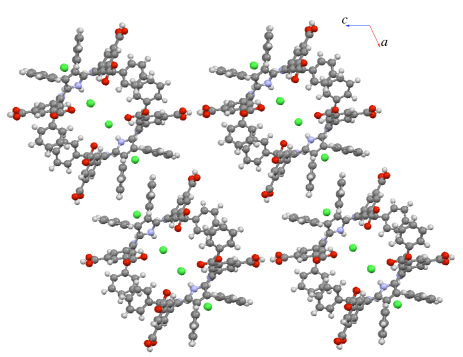

(b)

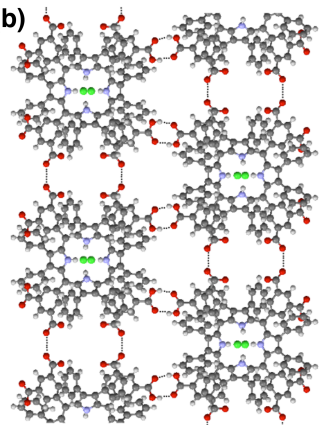

Fig. 4 Crystal structures of $\left[\mathrm{H}_{2} 4\right] \mathrm{Cl}_{2}$. (a) Nanochannel along the $b$-axis and (b) ladder-like Hydrogen-bonding network.

the mean plane of the diprotonated porphyrin cation to form hydrogen bonds between the pyrrolic NHs of $\left[\mathrm{H}_{2} \mathbf{1}\right]^{2+}$ and the oxygen atoms of the perchlorate ions (Fig S1a in ESI). ${ }^{14}$ The $\left[\mathrm{H}_{2} \mathbf{1}\right]^{2+}$ cations formed warped nanochannels both to the 5 crystallographic $a$ - and $b$-axis directions with intermolecular $\pi$ - $\pi$ stacking between the peripheral phenyl groups and the inner spaces were occupied with perchlorate ions and co-crystallized THF, EtOH and water molecules (see Fig. S1b in ESI). ${ }^{15}$

The crystal structure of $\left[\mathrm{H}_{2} 2\right]\left(\mathrm{ClO}_{4}\right)_{2}$ included the two counter 10 perchlorate ions, which interacted with the porphyrin dication similarly to the case of $\left[\mathrm{H}_{2} \mathbf{1}\right]\left(\mathrm{ClO}_{4}\right)_{2}$ (vide supra). The nanochannels formed by $\left[\mathrm{H}_{2} 2\right]^{2+}$ run both to the $n$ - and $n+90^{\circ}$ directions (Fig. 2a), and the height and width of the inner space are 3.1 and $6.8 \AA$, respectively. The inner spaces were occupied 15 by the perchlorate ions and co-crystallized EtOH molecules, ${ }^{15}$ and the number of included EtOH molecules was twenty-six in the unit cell. In the crystal, $\left[\mathrm{H}_{2} 2\right]^{2+}$ was linked with each other by complementary intermolecular hydrogen bonds of the carboxyl groups to form a 1-D molecular wire as depicted in Fig. 2b. The 20 hydrogen bonds also assisted mutual linking of the nanochannels as shown in Fig. S2a in ESI. In the hydrogen-bonding network, the complementary hydrogen bonds between the carboxyl groups linked the porphyrin nanochannels, in which the 1-D hydrogen bonding wires diagonally came across the nanochannels.

$\left[\mathrm{H}_{2} 3\right] \mathrm{Cl}_{2}$ was crystallized into a triclinic lattice and the two chloride ions were positioned above and below the mean plane of the diprotonated porphyrin dication to form hydrogen bonds between the pyrrollic NHs, similar to the case previously reported for $\left[\mathrm{H}_{2} \mathbf{1}\right] \mathrm{Cl}_{2}{ }^{9}$ In the crystal of $\left[\mathrm{H}_{2} \mathbf{3}\right] \mathrm{Cl}_{2}$, nanochannels were also

30 formed both along the $a$ - and $b$-axes and the channel of the $a$-axis was relatively warped (Fig. 3a). The heights and widths of the

inner spaces in the nanochannels were 3.0 and $6.3 \AA$ for the $a$ axis channel and 2.9 and $5.4 \AA$ for the $b$-axis channel, respectively. In the crystal of $\left[\mathrm{H}_{2} 3\right] \mathrm{Cl}_{2}$, the inner spaces also 35 included the chloride ions and co-crystallized $\mathrm{MeOH}$ and $\mathrm{H}_{2} \mathrm{O}$ molecules, ${ }^{15}$ and the numbers of the included solvent molecules per the unit cell were ten for $\mathrm{MeOH}$ and eight for $\mathrm{H}_{2} \mathrm{O}$. A hydrogen-bonding network was also observed for the crystal structure of $\left[\mathrm{H}_{2} 3\right] \mathrm{Cl}_{2}$ and the network was two-dimensionally 40 extended with the complementary hydrogen bonding by all the four carboxyl groups of $\left[\mathrm{H}_{2} 3\right]^{2+}$ as shown in Fig. 3 b. The fully complementary hydrogen bonds by the four carboxyl groups in $\mathrm{H}_{2} 3^{2+}$ stitched up the porphyrin nanochannels steadily (Fig. S3b in ESI).

${ }_{45}$ In the crystal structure of $\left[\mathrm{H}_{2} 4\right] \mathrm{Cl}_{2}$, the cation part of $\left[\mathrm{H}_{2} 4\right]^{2+}$ was capped with two chloride ions through the hydrogen-bonding, similar to the case of $\left[\mathrm{H}_{2} 3\right] \mathrm{Cl}_{2}$. A nanochannel structure, which ran along the $b$-axis direction as depicted in Fig. 4a, was also observed in the crystal structure of $\left[\mathrm{H}_{2} 4\right] \mathrm{Cl}_{2}$ and the channel size 50 was estimated to be $4.4 \times 4.8 \AA$. The inner space of the nanochannel was occupied by chloride ions and co-crystallized cyclohexane. The hydrogen-bonding patterns between the peripheral carboxyl groups were relatively complicated: Two of the eight carboxyl groups formed inter-molecular complementary ${ }_{55}$ hydrogen bonding pairs, other four formed hydrogen bonds with other carboxyl groups and co-crystallized with EtOH molecules, which resulted in one-dimensional chains of the porphyrins (Fig. 4b). The other two carboxyl-groups formed hydrogen bonds only with co-crystallized EtOH molecules. As a result of these ${ }_{60}$ hydrogen bonds, a ladder-like network structure of $\left[\mathrm{H}_{2} 4\right]^{2+}$ emerged and the space between the ladders was occupied with hydrogen-bonded solvent molecules. In addition, the hydrogenbonding network including EtOH molecules in one nanochannel is required for stabilizing the interactions between porphyrin ${ }_{65}$ components in the channel. Thus, the complementary hydrogen bonding has been demonstrated to play an important role in linking the nanochannels (Fig. S4c and d in ESI).

Thermogravimetric (TG) analyses of the porphyrin nanochannels were conducted to examine the stability of 70 nanochannels quantitatively. As previously reported, $\left[\mathrm{H}_{2} \mathbf{1}\right] \mathrm{Cl}_{2}$ exhibited a steep weight loss at $125{ }^{\circ} \mathrm{C}$ under $\mathrm{N}_{2}$ atomosphere. ${ }^{9 b}$ In order to compare the thermal stability of nanochannels involving hydrogen bonding networks, TG profiles were obtained for the crystalline samples of $\left[\mathrm{H}_{2} 2\right]\left(\mathrm{ClO}_{4}\right)_{2}, \quad\left[\mathrm{H}_{2} 3\right] \mathrm{Cl}_{2}$, and $75\left[\mathrm{H}_{2} 4\right] \mathrm{Cl}_{2}$, by increasing the temperature from room temperature to $400{ }^{\circ} \mathrm{C}$ with a ramp rate of $2{ }^{\circ} \mathrm{C} / \mathrm{min}$ under $\mathrm{N}_{2}$. From the room temperature to $c a$. $50{ }^{\circ} \mathrm{C}$, slight weight losses derived from evaporation of the residual solvent molecules on the crystal surfaces were observed for all the samples, thus, the weight losses 80 were normalized by the weights at $50{ }^{\circ} \mathrm{C}$. As shown in Fig. 5, the co-crystallized solvent molecules in $\left[\mathrm{H}_{2} 2\right]\left(\mathrm{ClO}_{4}\right)_{2}$ were evacuated around $150{ }^{\circ} \mathrm{C}$, and $\left[\mathrm{H}_{2} 2\right]\left(\mathrm{ClO}_{4}\right)_{2}$ was thermally decomposed around $350{ }^{\circ} \mathrm{C}$. On the other hand, the steep weight loss of nearly $30 \%$ around $150{ }^{\circ} \mathrm{C}$ was observed for $\left[\mathrm{H}_{2} 4\right] \mathrm{Cl}_{2}$ and the gradual ${ }_{85}$ weight loss lasted over $150{ }^{\circ} \mathrm{C}$. This gradual decrease resulted from the instability of $\left[\mathrm{H}_{2} 4\right] \mathrm{Cl}_{2}$ framework after the removal of co-crystallized solvent molecules. For $\left[\mathrm{H}_{2} 3\right] \mathrm{Cl}_{2}$, the weight loss of only $3 \%$ was observed around $230{ }^{\circ} \mathrm{C}$ and no successive weight loss was observed. At higher temperature more than 


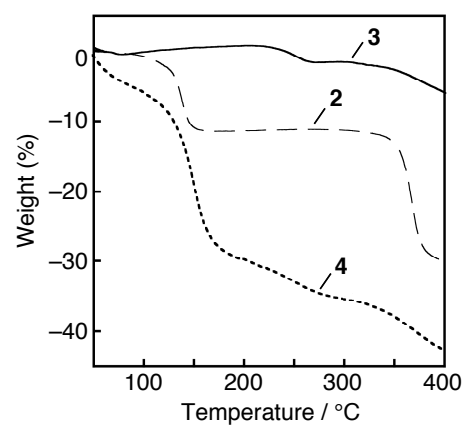

Fig. 5 TG profiles for $\left[\mathrm{H}_{2} 2\right]\left(\mathrm{ClO}_{4}\right)_{2}(--),\left[\mathrm{H}_{2} 3\right] \mathrm{Cl}_{2}(-\cdot-)$ and $\left[\mathrm{H}_{2} 4\right] \mathrm{Cl}_{2}(---$ ). The temperature increased to $400{ }^{\circ} \mathrm{C}$ with a ramp rate of $2{ }^{\circ} \mathrm{C} / \mathrm{min}$.

${ }_{5} 320^{\circ} \mathrm{C}$, a gradual weight loss less than $5 \%$ was observed. In addition, the powder X-ray diffraction patterns of $\left[\mathrm{H}_{2} 3\right] \mathrm{Cl}_{2}$ after the thermal treatment indicates that $\left[\mathrm{H}_{2} 3\right] \mathrm{Cl}_{2}$ maintained the crystallinity with slight disorder in contrast to the case of $\left[\mathrm{H}_{2} 4\right] \mathrm{Cl}_{2}$ (Fig. S6 in ESI). Despite the fact that the number of the 10 carboxyl groups in $\left[\mathrm{H}_{2} 3\right]^{2+}$ is less than $\left[\mathrm{H}_{2} 4\right]^{2+}$, the stability of the supramolecular structure of $\left[\mathrm{H}_{2} 3\right] \mathrm{Cl}_{2}$ was superior to that of $\left[\mathrm{H}_{2} 4\right] \mathrm{Cl}_{2}$. This indicates that the fully complimentary hydrogenbonding network observed in the single-crystal structure is quite important to stabilize the supramolecular structures.

\section{${ }_{15}$ Conclusion}

We have succeeded in stabilization of porphyrin nanochannel structures linked by hydrogen bonding among peripheral carboxyl groups. The TG profiles of the solid samples of hydrogen-bonded nanochannels were measured to observe the 20 weight loss of the evacuation of the co-crystallized solvent. The TG profile of $\left[\mathrm{H}_{2} 3\right] \mathrm{Cl}_{2}$ indicates that the supramolecular structure is stabilized by the complementary hydrogen-boding network as shown in Fig. 3 b even after the loss of the co-crystallized solvent molecules by the thermal treatment at $230{ }^{\circ} \mathrm{C}$. In the light of the

25 robustness even after loss of the included solvents, this strategy for stabilization of porphyrin nanochannels allows us to provide the possibility of the wide applications including gas storage in the inner spaces and heterogeneous catalysis with the catalytic activity of porphyrin cores and so on. Furthermore, the counter 30 anions included in the channels may also assist the guest inclusion by the interaction between the guest molecules.

\section{Notes and references}

${ }^{a}$ Department of Chemistry, Graduate School of Pure and Applied Sciences, University of Tsukuba, 1-1-1 Tennoudai, Tsukuba, Ibaraki 30535 8571, Japan. Fax: +81 29853 4323; Tel: +81 29853 4323; E-mail: kojima@chem.tsukuba.ac.jp

${ }^{b}$ Department of Material and Life Science, Graduate School of Engineering, Osaka University and ALCA, JST, 2-1 Yamada-oka, Suita, Osaka 565-0871, Japan

$4^{c}{ }^{c}$ Department of Bioinspired Science, Ewha Womans University, Seoul 120-750, Korea

$\dagger$ Electronic Supplementary Information (ESI) available: Experimental details, crystal structures of $\left[\mathrm{H}_{2} \mathbf{1}\right]\left(\mathrm{ClO}_{4}\right)_{2},\left[\mathrm{H}_{2} 2\right]\left(\mathrm{ClO}_{4}\right)_{2},\left[\mathrm{H}_{2} 3\right] \mathrm{Cl}_{2}$, and $\left[\mathrm{H}_{2} 4\right] \mathrm{Cl}_{2}, \mathrm{CCDC}$ reference numbers, Schematic description of linking 45 manners of the nanochannels by hydrogen bonds, and $\mathrm{N}_{2}$-adsorption and desorption isotherm at $77 \mathrm{~K}$, the powder X-ray diffraction patterns of $\left[\mathrm{H}_{2} 3\right] \mathrm{Cl}_{2}$ and $\left[\mathrm{H}_{2} 4\right] \mathrm{Cl}_{2}$. See DOI: $10.1039 / \mathrm{b} 000000 \mathrm{x} /$

\$ We appreciate Prof. Norimitsu Tohnai (Osaka University, Japan) his accommodation for XRD measurements.
501 (a) M. D. Joesten and L. J. Schaad, Hydrogen Bonding; M. Dekker: New York, 1974. (b) P. A. Kollman and L. C. Allen, Chem. Rev., 1972, 72, 283-303.

2 I. Ohmine and H. Tanaka, Chem. Rev., 1993, 93, 2545-2566.

3 (a) G. A. Jeffrey and W. Saenger, Hydrogen Bonding in Biological

55 Structures; Springer-Verlag: Berlin, 1994. (b) A. Majumdar and D. J. Patel, Acc. Chem. Res., 2002, 35, 1-11.

4 (a) W. P. Jencks, Chem. Rev., 1972, 72, 705-718. (b) A. S. Borovik, Acc. Chem. Res., 2005, 38, 54-61. (c) I. R. Greig, Chem. Soc. Rev., 2010, 39, 2272-2301.

605 (a) G. A. Hembury, V. V. Borovkov and Y. Inoue, Chem. Rev., 2008, 108, 1-73. (b) V. Amendola, L. Fabbrizzi and L. Mosca, Chem. Soc. Rev., 2010, 39, 3889-3915. (c) K. Kobayashi, M. Koyanagi, K. Endo, H. Masuda and Y. Aoyama, Chem. Eur. J., 1998, 4, 417-424. (d) P. Bhyrappa, S. R. Wilson and K. S. Suslick, J. Am. Chem. Soc., 1997, 119, 8492-8502. (e) Y. Diskin-Posner and I. Goldberg, Chem. Commun., 1999, 1961-1962. (f) I. Goldberg, Chem. Commun., 2005, 1243-1254 and references therein. (g) I. Radivojevic, I. Likhtina, X. Shi, S. Singha and C. M. Drain Chem. Commun., 2010, 47, 16431645. (h) Y. Zeng, Y. Pratumyot, X. Piao and D. Bong, J. Am. Chem. Soc., 2012, 134, 832-835.

6 (a) S. Bureekaew, S. Horike, M. Higuchi, M. Mizuno, T. Kawamura, D. Tanaka, N. Yanai and S. Kitagawa, Nat. Mater., 2009, 8, 831836. (b) S. C. Sahoo, T. Kundu and R. Banerjee, J. Am. Chem. Soc., 2011, 133, 17950-17958.

757 (a) L. Brunsveld, B. J. B. Folmer, E. W. Meijer and R. P. Sijbesma, Chem. Rev., 2001, 101, 4071-4097. (b) L. J. Prins, F. De Jong, P. Timmerman and D. N. Reinhoudt, Nature, 2000, 408, 181-184. (c) J. Otsuki, E. Nagamine, T. Kondo, K. Iwasaki, M. Asakawa and K. Miyake, J. Am. Chem. Soc., 2005, 127, 10400-10405. (d) Q. Yuan, Y. Xing and E. Borguet, J. Am. Chem. Soc., 2010, 132, 5054-5060.

8 (a) N. Malek, T. Maris, M.-E. E. Perron and J. D. Wuest, Angew. Chem. Int. Ed., 2005, 44, 4021-4025. (b) N. Malek, T. Maris, M. Simard and J. D. Wuest, J. Am. Chem. Soc., 2005, 127, 5910-5916. (c) Y. He, S. Xiang and B. Chen, J. Am. Chem. Soc., 2011, 133, 14570-14573.

9 (a) R. Harada and T. Kojima, Chem. Commun., 2005, 716-718. (b) T Kojima, T. Nakanishi, R. Harada, K. Ohkubo, S. Yamauchi and S. Fukuzumi, Chem. Eur. J., 2007, 13, 8714-8725. (c) T. Nakanishi, T. Kojima, K. Ohkubo, T. Hasobe, K. Nakayama and S. Fukuzumi, Chem. Mater., 2008, 21, 7492-7500.

10 (a) C. J. Medforth, M. O. Senge, K. M. Smith, L. D. Sparks and J. A. Shelnutt, J. Am. Chem. Soc., 1992, 114, 9859-9869. (b) S. Gentemann, C. J. Medforth, T. P. Forsyth, D. J. Nurco, K. M. Smith, J. Fajer and D. Holten, J. Am. Chem. Soc., 1994, 116, 7363-7368. (c) R. Harada, Y. Matsuda, H. Okawa and T. Kojima, Angew. Chem. Int. Ed., 2004, 43, 1825-1828.

11 (a) T. Nakanishi, K. Ohkubo, T. Kojima and S. Fukuzumi, J. Am. Chem. Soc., 2009, 131, 577-584. (b) T. Kojima, T. Honda, K. Ohkubo, M. Shiro, T. Kusukawa, T. Fukuda, N. Kobayashi and S. Fukuzumi, Angew. Chem. Int. Ed., 2008, 47, 6712-6716. (c) T. Honda, T. Nakanishi, K. Ohkubo, T. Kojima and S. Fukuzumi, J. Am. Chem. Soc., 2010, 132, 10155-10163.

12 M. Sankar, T. Ishizuka, Z. Wang, T. Ma, M. Shiro and T. Kojima, J. Porphyrins Phthalocyanines, 2011, 15, 421-432.

10513 Dichloride salt of $\mathbf{2}$ did not give a nanochannel structure due to the hydrogen bonding interaction between the peripheral carboxyl groups and the counter chloride ions. unpublished results.

14 One of the two perchlorate ions of $\left[\mathrm{H}_{4} 2\right]\left(\mathrm{ClO}_{4}\right)_{2}$ was fixed with the two hydrogen bonds between two pyrrolic NHs and the two oxygen atoms, but the other was bound to one pyrrolic NH with only one hydrogen bond and thus it was found to disorder to direct to one of the two pyrrolic NHs.

15 The co-crystallized solvents included in the porphyrin nanochannels for all the four structures were highly disordered and thus deleted by using the SQUEEZE program. P. V. D. Sluis and A. L. Spek, Acta Crystallogr. 1990, A46, 194-201. 